\title{
Risk of obstructive sleep apnoea syndrome among in-patients at a neuropsychiatric hospital in Nigeria: a short report
}

\author{
Bawo O James, Chinwe F. Inogbo, Atim O. Archibong
}

Federal Neuro-Psychiatric Hospital, Benin-City, Nigeria.

\begin{abstract} using a socio-demographic questionnaire and the Berlin questionnaire. of atypical antipsychotics $(\mathrm{p}=0.48)$. associated with this high risk.

DOI: http://dx.doi.org/10.4314/ahs.v15i3.34

\section{Introduction}

Sleep disturbances are common complaints among individuals with mental illness ${ }^{1}$. These disturbances are associated with increased morbidity and mortality ${ }^{2-3}$. Obstructive sleep apnea syndrome (OSA) is a breathing related sleep disorder associated with partial or complete upper airway obstruction and is a common co-morbidity in individuals with mental illness ${ }^{3}$.

The relationship between OSA and mental illness is complex. The clinical features of OSA, like poor sleep quality, daytime fatigue or somnolence may overlap with symptoms of certain mental illnesses ${ }^{4}$. Psychotropic drug-induced weight gain and a sedentary life style due to psychomotor retardation in individuals with mental illness may also increase the risk for the development of $\mathrm{OSA}^{3}$.
\end{abstract}

Background/Objectives: Sleep problems are commonly reported by persons with severe mental illness. Obstructive sleep apnoea syndrome (OSA) is commonly co-morbid with mental illness. Screening for OSA and its subsequent management may improve outcomes in this patient population. We screened for risk of OSA among in-patients with severe mental illness to determine its prevalence as well as its correlates using a socio-demographic questionnaire and the Berlin questionnaire Methods: A cross sectional descriptive exploratory survey of in-patients $(n=89)$ at a regional Neuro- Psychiatric hospital

Results: Eighteen patients (18/89; 20.9\%) were classed as high risk for OSA. High risk for OSA was significantly associated with a higher body mass index; BMI $(\mathrm{p}<0.01)$, but not gender $(\mathrm{p}=0.53)$, diagnoses $(\mathrm{p}=0.84)$, co-morbidity $(\mathrm{p}=0.73)$ or use

Conclusion: Patients with severe mental illness are at high risk for OSA with being overweight higher BMI significantly

Keywords: obstructive sleep apnoea; severe mental illness; Nigeria, in-patients

Cite as: James BO, Inogbo CF, Archibong AO. Risk of obstructive sleep apnoea syndrome among in-patients at a neuropsycbiatric bospital in Nigeria: a short report. Afri Health Sci. 2015;15(3):967-71. doi: http:// dx.doi.org/10.4314/abs.v15i3.34

\section{Corresponding author: \\ Bawo O James, \\ Federal Neuro-Psychiatric Hospital, \\ Benin-City, Nigeria. \\ E-mail: bawojames@yahoo.com, \\ Phone: +234-8023715213}

In Western countries, the prevalence of OSA is reported to be between $5 \%$ and $10 \% 0^{5-6}$ in the general population. Its prevalence is on average higher in the mentally $\mathrm{ill}^{2-3}$. In Nigeria, the prevalence of OSA has been described in various targeted groups; heart failure patients ${ }^{4}$, and hypertensive patients ${ }^{7}$. However there is no study on the risk of sleep apnea syndrome among the mentally ill who have an increased risk for the syndrome. This exploratory study aimed to determine the prevalence and correlates of risk of obstructive sleep apnea syndrome among in-patients at a regional neuropsychiatric hospital in Nigeria. It is expected that the findings of this report will increase the awareness of psychiatrists concerning this co-morbidity in sub-Saharan Africa, as well as argue for an intensive assessment of sleep problems in mentally ill patients who do not respond to interventions to improve their sleep

\section{Materials and methodology \\ Setting}

A cross-sectional study was carried out on the in-patients at the Federal Neuro- Psychiatric Hospital (FNPH), Benin-City, Nigeria over a 4 month period (July - October, 2013). The FNPH is a 220-bed hospital that offers both in- and out-patient psychiatric services. In-patient care is provided at the 'acute' and 'stable' wards in the hospital. 


\section{Participants}

Eighty-nine (89) in-patients out of 112 in-patients aged between 18 and 65 years were recruited for this study. These were patients who met the diagnostic criteria according to ICD-10 for a psychiatric disorder. Patients who were admitted into the acutely ill wards were excluded from the study and only participants who were mentally stable and able to understand the nature and purpose of the study were recruited. Patients in the drug treatment wards, general adult wards were thus surveyed. Due to age restrictions, we excluded patients in the child and adolescent wards

\section{Measures}

Socio-demographic and clinical characteristics of each patient including age, gender, marital status, diagnosis, duration of illness, history of diabetes and hypertension and previous admissions, were assessed using the socio-demographic questionnaire.

\section{Berlin questionnaire}

Sleep apnea risk was determined using the Berlin Questionnaire ${ }^{8}$ which is a 10 - item instrument designed to assess risk of OSA in 3 categories of questions relating to sleep apnea. Individuals with positive responses to 2 or more categories were considered to have a high likelihood of OSA and less than 2 positive or no responses were considered low risk. A score of 2 and above for each category was considered a positive response.

\section{Ethics}

Ethical clearance was sought and obtained from the Ethics Committee of the FNPH, Benin City. Each participant was assessed by one of the researchers and if found to be in a stable mental state and able to understand the nature and purpose of the study was recruited after filling the informed consent forms. Confidentiality and anonymity was assured and clients were told they could withdraw with no untoward consequence. Those found to be at high risk were offered referrals to a specialist for follow-up.

\section{Procedure}

Written informed consent was obtained from each participant after explanation of the study protocol. The study instruments were administered to each participant by the researchers.

Each patient's body weight in kilograms, height in meters, neck circumference in centimetres and blood pressure were measured and the interviews completed in English language.

\section{Data analysis}

Statistical analysis was done using the Statistical Package for the Social Sciences version 16 (SPSS 16.0). Descriptive statistics was used to summarize the data. Comparisons between categorical and continuous variables and high risk for OSA were performed using the chi-square test and t-test respectively. Level of significance was set at $\mathrm{p}<0.05$.

\section{Results}

Of the eighty nine (89) in-patients recruited for this study, majority were males $(n=62 ; 69.7 \%)$. The age range of the whole sample was between 18 and 63 years with mean age of $35.39 \pm 10.57$ years; the modal age group were those between 18 and 30 years $(n=36$; $40.4 \%)$. Most were single ( $\mathrm{n}=64 ; 71.9 \%)$, and Christian $82(92.1 \%)$.

Fifty five participants $(63.2 \%)$ were being managed for schizophrenia, $31(35.6 \%)$ for bipolar affective disorder and one $(1.2 \%)$ for severe depression with psychotic symptoms. The mean duration of illness was 55.28 (65.77) weeks. Thirty eight patients were receiving in-patient care for the first time. Fifteen $(16.9 \%)$ had a physical co-morbidity which was hypertension, none had a history of diabetes. Fifty four (62.1\%) were on atypical antipsychotics, and $13(14.9 \%)$ had co-morbid psychoactive substance use. Thirty four (38.2\%) were overweight; with a BMI greater than 25. See Table 1. 
Table 1: Socio-demographic and clinical characteristics of participants

\begin{tabular}{|c|c|}
\hline Variable & Number (\%) \\
\hline $\begin{array}{l}\text { Age class } \\
18-30 \\
31-40 \\
41-50 \\
>50 \\
\end{array}$ & $\begin{array}{l}36(40.4) \\
29(32.6) \\
15(16.9) \\
9(10.1) \\
\end{array}$ \\
\hline $\begin{array}{l}\text { Gender } \\
\text { Male } \\
\text { Female } \\
\end{array}$ & \begin{tabular}{|ll}
62 & $(69.7)$ \\
27 & $(30.3)$ \\
\end{tabular} \\
\hline $\begin{array}{l}\text { Religion } \\
\text { Christian } \\
\text { Islam } \\
\end{array}$ & $\begin{array}{l}82(92.1) \\
7(7.9) \\
\end{array}$ \\
\hline $\begin{array}{l}\text { Marital Status } \\
\text { Single } \\
\text { Married } \\
\text { Separated/divorced/widowed }\end{array}$ & $\begin{array}{l}64(71.9) \\
20(22.5) \\
5(5.6) \\
\end{array}$ \\
\hline $\begin{array}{l}\text { Number of previous hospital } \\
\text { admissions } \\
\text { None } \\
1 \\
2-4 \\
\geq 5\end{array}$ & $\begin{array}{l}38(42.7) \\
14(15.7) \\
33(37.1) \\
4(4.5)\end{array}$ \\
\hline $\begin{array}{l}\text { History of hypertension } \\
\text { Yes } \\
\text { No } \\
\end{array}$ & $\begin{array}{l}15(16.9) \\
74(83.1) \\
\end{array}$ \\
\hline $\begin{array}{l}\text { History of diabetes } \\
\text { Yes } \\
\text { No } \\
\end{array}$ & $89(100)$ \\
\hline $\begin{array}{l}\text { BMI range } \\
>18.5 \\
18.5-24.9 \\
\geq 25.0 \\
\end{array}$ & \begin{tabular}{|l}
$5(5.6)$ \\
$50(56.2)$ \\
$34(38.2)$ \\
\end{tabular} \\
\hline $\begin{array}{l}\text { Berlin category score } \\
\text { Category } 1 \\
\geq 2 \\
<2 \\
\text { Category } 2 \\
\geq 2 \\
<2 \\
\text { Category } 3 \\
\geq 2 \\
<2 \\
\end{array}$ & \begin{tabular}{|ll}
27 & $(30.3)$ \\
62 & $(69.7)$ \\
& \\
21 & $(23.6)$ \\
68 & $(76.4)$ \\
& \\
21 & $(23.6)$ \\
68 & $(76.4)$ \\
\end{tabular} \\
\hline
\end{tabular}

Eighteen $(20.7 \%)$ in-patients were classified as having high risk for OSA using the Berlin questionnaire. High risk for OSA was significantly associated with a higher average BMI $(\mathrm{p}<0.01)$, but not weight $(\mathrm{p}=0.06)$, diagnosis $(p=0.84)$, gender $(p=0.53)$, use of atypical antip- sychotics $(\mathrm{p}=0.48)$ or physical co-morbidity $(\mathrm{p}=0.73)$. See Table 2.

Compared to the group of patients with normal range BMI, there was an increased risk of OSA in the underweight $(\mathrm{R} R=1.5)$ and overweight $(\mathrm{R}=2.8)$ groups. 
Table 2: Comparison of continuous variables and risk for OSA

\begin{tabular}{|l|l|l|l|l|}
\hline Variable & High risk OSA & Low risk OSA & $\mathbf{t}$ & $\mathbf{p}$ \\
\hline Age (years) & $35.78(9.53)$ & $35.29(10.89)$ & 0.19 & 0.86 \\
& & & & \\
\hline Duration of illness (months) & $62.76(53.32)$ & $47.90(69.87)$ & 0.53 & 0.52 \\
\hline Height (metres) & $1.70(0.76)$ & $1.73(0.09)$ & -1.08 & 0.23 \\
\hline Weight $(\mathrm{kg})$ & $78.06(16.05)$ & $71.26(12.86)$ & 1.89 & 0.06 \\
\hline BMI $(\mathrm{kg} / \mathrm{m} 2)$ & $26.73(5.27)$ & $23.84(3.66)$ & 2.70 & 0.01 \\
\hline
\end{tabular}

\section{Discussion}

We found that a fifth of in-patients in this exploratory study were at high risk for OSA using the Berlin questionnaire. Though significant associations were not observed between high risk for OSA and most socio-demographic and clinical variables, patients at high risk for OSA were on average overweight, older, using atypical antipsychotics and receiving inpatient care for schizophrenia.

The strength of our findings is limited by its small sample size, the absence of a reliable witness to corroborate sleep habits and a bias for patients who are severely mentally ill. Furthermore, we only employed the use of a screening instrument and each participant at high risk for OSA would require a diagnostic assessment especially if treatment may be initiated. The Berlin Questionnaire has not been validated as well for use in psychiatric populations, in which illness symptoms and sedative effects of medications may confound the sensitivity of the screening instrument. A study determining its cut-off for OSA risk is still required and limits the strength of our findings.

The prevalence reported in this study is low when compared to similar studies in psychiatric populations. Weight appears to correlate strongly with OSA risk, thus a high rate of $54.1 \%$ observed in the study by Soreca and colleagues ${ }^{2}$ was among bipolar patients who were all overweight. In our sub sample of overweight patients the risk for OSA was as high as $48 \%$. Furthermore, we also observed that the risk of OSA increased when compared to baseline (normal weight) in the underweight and overweight patient sub-groups. Compared to studies involving apparently healthy populations in Nigeria and employing the use of the same screening instrument, we observed that risk for
OSA was higher in our sample compared to apparently healthy persons ${ }^{10,11}$, but lower when compared to heart failure patients ${ }^{4}$. This finding is consistent with previous reviews that report a higher prevalence of OSA in persons with mental illness compared to apparently healthy populations ${ }^{3}$.

Unlike in a previous report, we found an association between OSA risk and $\mathrm{BMI}^{9}$. Concerns about weight have been highlighted by clinicians in developing countries. With atypical antipsychotics becoming more affordable and little emphasis being placed on dietary regimens and exercise for the chronically mentally ill, it may become evident that strategies to reduce weight or control its rise are cardinal to optimizing treatment outcomes. There is some evidence that use of atypical antipsychotics is associated with a greater severity of $\mathrm{OSA}^{12}$.

\section{Conclusion}

We report that there was a moderate risk for OSA among patients with severe mental illness. Body mass index (BMI) is strongly correlated with OSA risk and may be a modifiable risk factor for OSA.

\section{Author contribution:}

BOJ conceived the study, performed the data analysis and approved the final draft. CFI \& AOA wrote the initial draft, collected the data and approved the final draft of the manuscript.

\section{References}

1. Ohayon MM. Prevalence of DSM-IV diagnostic criteria of insomnia: Distinguishing insomnia related to mental disorders from sleep disorders. J Psycbiatr Res 1997; 31 (3): 333 PubMed -346

2. Soreca I, Levenson J, Lotz M, Frank E, Kupfer DJ. 
Sleep apnea risk and clinical correlates in patients with bipolar Disorder. Bipolar Disord. 2012; 14(6): $672 \mathrm{Pu}-$ bMed -676.

3. Lin W-C, Winkelman JW. Obstructive sleep apnea and severe mental illness: evolution and consequences. Curr Psychiatry Rep. 2012; 14(5): 503 PubMed -10

4. Akintunde AA. Snoring and risk for obstructive sleep apnea among Nigerians with heart failure: Prevalence and clinical correlates. Heart Views 2013; 14: 17-21 PubMed .

5. Young T, Peppard PE, Gottlieb DJ. Epidemiology of Obstructive sleep apnoea: a population health perspective. Am J Respir Crit Care Med. 2002; 165:1217-39.

6. Tishler PV, Larkin EK, Schluchter MD, et al. Incidence of sleep-disordered breathingin an urban adult population: the relative importance of risk factors in the development of sleep-disordered breathing. JAMA 2003; 289:2230- PubMed ;2237

7. Akintunde AA, Okunola OO, Oluyombo R, Oladosu YO, Opadijo OG. Snoring and obstructive sleep apnoea syndrome among hypertensive Nigerians: prevalence and clinical correlates. Pan Afr Med J. 2012; 11:75.

8. Netzer NC, Stoohs RA, Netzer CM, Clark K, Strohl KP. Using the Berlin Questionnaire to identify patients at risk for the sleep apnea syndrome, Ann Intern Med. 1999;131(7):485-91.

9. Ancoli-Israel S, Martin J, Jones DW, Caligiuri M, Patterson T, Harris MJ, et al. Sleep-disordered breathing and periodic limb movements in sleep older patients with schizophrenia. Biol Psychiatry, 1999; 45:1426-32 PubMed

10. Adewole OO, Hakeem A, Fola A, Anteyi E, Ajuwon Z, Erhabor G. Obstructive sleep apnea among adults in Nigeria. J Natl Med Assoc. 2009; 101(7):720 PubMed -5. 11. Ozoh OB, Okubadejo NU, Akanbi MO, Dania MG. High-risk of obstructive sleep apnea and excessive daytime sleepiness among commercial intra-city drivers in Lagos metropolis. Niger Med J. 2013; 54(4):224 PubMed $-9$.

12. Shirani A, Paradiso S, Dyken ME. The impact of atypical antipsychotic use on obstructive sleep apnea: a pilot study and literature review. Sleep Med. 2011; 12(6):591-7. 